\title{
Unmet supportive care needs and its relation to quality of life among adult acute leukaemia patients in China: a cross- sectional study
}

Yan Jie ${ }^{1 \dagger}$, Ying Wang ${ }^{1 \dagger}$, Jingyi Chen ${ }^{1}$, Chunfeng Wang ${ }^{1}$, Yingchun $\mathrm{Lin}^{2}$, Rong $\mathrm{Hu}^{1 *}$ (D) and Yong $\mathrm{Wu}^{3^{*}}$

\begin{abstract}
Background: Patients with acute leukaemia (AL) usually require prolonged periods of hospitalisation. The treatment and clinical symptoms may lead to patients' supportive care needs (SCNs) not being met and impairs their quality of life (QoL). Studies on QoL and SCNs among AL patients are limited. This study aimed to identify the unmet SCNs and its relation to QoL of adult AL patients in China.

Methods: This multicentre cross-sectional study recruited 346 participants to complete a self-developed questionnaire, detailing demographic information and disease-related variables. A 34-item Supportive Care Needs Survey (SCNS-SF34) was used to identify unmet SCNs, and the Functional Assessment of Cancer Therapy-Leukaemia (FACT-Leu) questionnaire measured patients' QoL.

Results: Unmet SCN rates for the 34 items ranged from 17.6 to $81.7 \%$. Patients' needs were high for health systems and information, but low in the sexual domain. The results reveal nine factors associated with the unmet SCNs of adult AL patients, including marital status, original residence, age, education, occupation, other diseases, chemotherapy course, disease course, and treatment stage $(p<0.05)$. The total score of the FACT-Leu negatively correlated with the SCNS-SF34 in the physical/daily living $(r=-0.527, p<0.01)$, psychological $(r=-0.688, p<0.01)$, sexual $(r=-0.170, p<0.01)$, patient care and support $(r=-0.352, p<0.01)$, and health systems and information $(r=-0.220, p<0.01)$ domains.

Conclusions: Adult AL patients exhibit a high demand for unmet SCNs, especially in the domain of health systems and information. There was a significant association between patients' unmet SCNs and QoL. Future research should develop tailored interventions to address the unmet SCNs of adult AL patients, to further improve their QoL.
\end{abstract}

Keywords: Acute leukaemia, Supportive care, Cancer patients, Life quality, Needs domains, Chemotherapy

\footnotetext{
* Correspondence: ronghu1246@fjmu.edu.cn; wuyong9195@126.com

${ }^{\dagger}$ Ying Wang and Jie Yan are first co-authors.

'School of Nursing, Fujian Medical University, NO.1 Xueyuan Road, Shangjie Town, Minhou County, Fuzhou City 350122, Fujian Province, China

${ }^{3}$ Department of Hematology, Fujian Medical University Union Hospital, No. 29 Xinquan Road, Gulou District, Fuzhou City 350001, Fujian Province, China

Full list of author information is available at the end of the article
}

(c) The Author(s). 2020 Open Access This article is licensed under a Creative Commons Attribution 4.0 International License, which permits use, sharing, adaptation, distribution and reproduction in any medium or format, as long as you give appropriate credit to the original author(s) and the source, provide a link to the Creative Commons licence, and indicate if changes were made. The images or other third party material in this article are included in the article's Creative Commons licence, unless indicated otherwise in a credit line to the material. If material is not included in the article's Creative Commons licence and your intended use is not permitted by statutory regulation or exceeds the permitted use, you will need to obtain permission directly from the copyright holder. To view a copy of this licence, visit http://creativecommons.org/licenses/by/4.0/ The Creative Commons Public Domain Dedication waiver (http://creativecommons.org/publicdomain/zero/1.0/) applies to the data made available in this article, unless otherwise stated in a credit line to the data. 


\section{Background}

Leukaemia is a heterogeneous group of haemopoietic cancers and the tenth leading cause of cancer death worldwide [1]. According to Global Cancer Statistics 2018, there were 437,033 new cases of leukaemia in 2018, of which 309,006 (70.7\%) died, corresponding to a very high mortality rate [2]. In China, there were nearly 75,300 new diagnoses of leukaemia, and approximately 53,400 leukaemia patients died, in 2015 [3]. The incidence of acute leukaemia (AL) has moderate increase from 1992 to 2017, with an estimated 26,090 new cases (including 6150 acute lymphoblastic leukemia (ALL) and 19,940 acute myeloblastic leukemia (AML)) diagnosed in the United States in 2020 [4]. The diagnosis and treatment of the disease can cause clinical symptoms and psychologically burden AL patients.

AL develops rapidly and can cause several clinical symptoms, including fever, fatigue, anaemia, bleeding, and infection [5]. Chemotherapy, as an effective treatment, can improve the overall survival rate of patients with AL [6]. However, the side effects of chemotherapy leads to patients with significant physical and psychological challenges, which affects their quality of life (QoL) [7]. Additionally, AL patients undergoing induction chemotherapy usually require prolonged periods of hospitalisation, typically lasting from three to four weeks $[8,9]$. Treatment and clinical symptoms of cancer can lead to enduring negative consequences for patients, including physical, psychological, social support and financial problems $[10,11]$. These negative consequences may further lead to patients' supportive care needs (SCNs) not being met.

Due to the lack of knowledge of AL, the skills required to address symptoms can trigger multi-domain needs (information, emotional, spiritual, social, or physical needs) throughout the treatment process. SCN is broadly defined as "the provision of the necessary services for those living with or affected by cancer to meet their informational, emotional, spiritual, social, or physical needs during their diagnostic, treatment, or follow-up phases encompassing issues of health promotion and prevention, survivorship, palliation, and bereavement." [12] Currently, most studies on SCNs for cancer patients are conducted in western countries [13], or in areas with well-funded health care systems areas, such as Hong Kong [14], Taiwan [15] and Japan [16]. SCNs may vary depending on the patient's cultural background [13]. Patients have been reported to be better able to cope with cancer by receiving quality supportive care [17].

Today, more attention is being paid to meeting the needs of patients suffering from other types of cancer, such as prostate and breast cancer, in order to improve cancer patients' QoL [18, 19]. Previous studies have shown that patients with AL have a low QoL [20].
Reduced QoL may be associated with psychological disorders or recurrence [21-23]. The relationship between the QoL and the SCNs of patients with cancer has recently been recognized [24]. Addressing the unmet SCNs of cancer patients in time, can improve the poor QoL of patients and increase survival rates [18, 25, 26]. Identifying unmet supportive needs can improve the psychological well-being and QoL of cancer patients, and guide clinical practice [27]. Improving the quality of care is evidence-based and addresses patients' unmet SCNs [28]. Therefore, assessing a patient's needs should take into account their preferences, to identify areas of unmet needs and cross-cultural influences [29].

This study aimed to: (i) investigate the unmet SCNs of adult AL patients; (ii) explore the factors associated with unmet SCNs of adult AL patients; and (iii) assess the relationship between unmet SCNs and the QoL of adult AL patients, on mainland China.

\section{Methods \\ Study design and participants}

This is a multicentre cross-sectional study, using a convenience sampling method to collect data. All AL adult patients who were referred to the departments of haematology of the three largest tertiary hospitals in Fuzhou, China, including the Fujian Medical University Union Hospital, the First Affiliated Hospital of Fujian University, and the Fujian Provincial Hospital between April 2017 and January 2018 were eligible for this study.

The selection criteria for adult AL patients included: (1) over 18 years of age; (2) a definitive AL diagnosis, based on a blood disease diagnosis and efficacy standard, (3) able to communicate fluently in Mandarin Chinese, and (4) the patient is aware of their cancer diagnosis and is willing to participate in the study. Patients were excluded if they had severe vital organ disease, or mental or cognitive disorders, such as dementia, loss of consciousness, or delirium. The proposed sample size was within five to ten times the number of items on the main scale of this study [30]. Therefore, as the Supportive Care Needs Survey form (SCNS-SF34) contains 34 items, it was estimated that 170 to 340 participants were required.

In total, 346 patients who were newly diagnosed or under therapy were invited to participate in the survey, and 325 (93.9\%) completed the questionnaire. Patients who declined to participant provided reasons, including their illness $(n=$ $15)$, lack of interest $(n=3)$, or lack of time $(n=3)$. Nineteen returned questionnaires were excluded from the final analyses, due to missing data. This resulted in a final sample size of 306 (88.4\% of invited participants).

\section{Procedures}

Data were collected by four dedicated investigators on each inpatient's bed through face-to-face interviews in 
haematology wards. After evaluating patients for eligibility, and inviting them to participate, consultations were held with interested recruits. Potential participants were identified from the hospital's electronic medical records. Prior to registration, all participants were informed of the objectives of the study and their rights. All participants voluntarily signed informed consent forms and were encouraged to complete socio-demographic information questionnaire, the SCNS-SF34 and FACT-Leu independently. Each questionnaire required between 10 and $30 \mathrm{~min}$ to complete. However, assistance from the investigator was available if participant has low vision or other disabilities. After each participant submitted the questionnaire, the investigator reviewed it and asked the participant to fill in any missing items. Imputing the missing values will be conducted when a subject completes only part of the questionnaire. In the case where less than half of the items within a domain are missing, we will impute a value that is equal to the mean for the individual of the other items in that domain [31]. The research followed the supportive care need framework [32], to explore unmet supportive care needs, which are conceptualized as influencing factors on long-term health outcomes, such as QoL.

\section{Measurements}

A self-reported questionnaire that includes two sections, was administered to collect data. The first section obtained the sociodemographic and clinical characteristics of adult AL patients. The second section includes the Supportive Care Needs Survey form (SCNS-SF34) and the Functional Assessment of Cancer TherapyLeukaemia (FACT-Leu) questionnaire. Participants completed the questionnaire, based on their actual experiences from the previous week.

\section{Participants' sociodemographic and clinical characteristics}

A questionnaire was used to collect sociodemographic information, including age, gender, marital status, religion, education and occupation. The clinical characteristics obtained, include the type of AL, the presence of absence of other diseases, the disease course, the chemotherapy course, the treatment stage, and whether the patient received initial treatment. Patients' medical records were collected from the patients' electronic records, with hospital permission.

\section{The Chinese version of supportive care needs survey-short form 34 (SCNs-SF34)}

This study employed the SCNS-SF34 to measure the unmet SCNs of adult AL patients. The SCNS-SF34 comprises 34 items with five domains: physical/daily living (5 items), psychological (10 items), patient care and support (5 items), sexuality ( 3 items), and health system information (11 items). Standardised scales were used to analyse SCN domains. For each item, patients were asked to indicate their level of unmet need over the last month. Patients could rate each item on a five-point Likert scale: $1=$ not applicable, $2=$ satisfied, $3=$ low need, $4=$ moderate need, and $5=$ high need. The percentage of unmet SCNs were evaluated. According to SCNS-SF34 scoring instructions [33], the standard score of each domain were calculated by $\mathrm{n} \times 100 /(\mathrm{m} \times(\mathrm{k}-1))$, which rescaling to a 0-100 range (m equals the number of each domain and $\mathrm{k}$ means the value of the maximum response for each item, $\mathrm{n}$ equals the result of summing the individual items, subtracting $\mathrm{m}$ ) [34]. Higher scores indicate more unmet needs of help. Cronbach's alpha of five domains of SCNS-SF34 ranged from 0.78 to 0.92 [18]. In this study, we divided the unmet SCNs of each domain into two groups: "no/low demand (including not applicable/satisfied/low need)" and moderate/high demand". Across five domains, the rank of each entry and percentage of moderate/high demand of unmet SCNs were evaluated. The SCNS-SF34 has been validated in Chinese cancer patients [35].

\section{The Chinese version of the functional assessment of cancer therapy-Leukaemia (FACT-Leu)}

Patient QoL was measured using the Chinese version of the Functional Assessment of Cancer Therapy-Leukaemia (FACT-Leu) questionnaire [36], which contains 27 Functional Assessment of Cancer Therapy-General (FACT-G) items and 17leukemia-specific items, comprising the physical well-being (PWB, 7 items), social/family well-being (SWB, 7 items), emotional well-being (EWB, 6 items), functional well-being (FWB, 7 items) and Leukaemiaspecific subscale (LEUS, 17 items). The items were assessed according to a five-point Likert scale $(0=$ not at all; $1=$ a little bit; $2=$ somewhat; $3=$ quite a bit; and $4=$ very much). The item scores were summed up to give the scores for each domain and the total score. Higher scores indicated better QOL. The score ranges from 0 to 176 , with higher scores indicating better QoL. The internal consistency of all FACT-Leu subscales and aggregated scores was high (Cronbach's alpha from 0.75 to 0.96 ). The Chinese version of FACT-Leu was shown to be reliable for measuring QoL in leukaemia patients [36].

\section{Statistical analysis}

Data from 306 adult AL patients met the eligibility criteria and were included in this study. A database was created using EpiData3.1 software (The EpiData Association, Odense, Denmark), and the data were each input by two researchers. The analysis was performed using IBM SPSS 22.0 (Armonk, NY, USA). Descriptive statistics were used to summarize the sociodemographic and clinical characteristics of adult AL patients. Categorical 
variables are presented as frequencies (n) and percentages (\%); continuous variables are presented as mean \pm standard deviation (SD) or median (M); the interquartile range (IQR) depends on the results of the normality test. Independent-sample t-tests (for two groups) or one-way analyses of variance (for multiple groups) were conducted to analyse the influence of patients' sociodemographic and clinical characteristics on unmet SCNs. Multivariate logistic regression was used to analyse the relevant factors affecting patients' unmet $\mathrm{SCNs}$, and the odds ratios (ORs) and 95\% confidence interval (CI) were calculated. The correlation between unmet SCNs and the QoL of adult acute leukaemia patients was examined using Spearman's rank correlation or Pearson correlation. All significance tests were two-sided and the level of significance was set at $p<0.05$.

\section{Results}

\section{Participants' characteristics}

Table 1 showed the characteristics of the adult AL patients. Of the research sample of 306 participants, the elderly AL patients (ages older than 60) accounted for $13.4 \%$. The majority of patients $(52.0 \%)$ were male and 227 (74.2\%) were married. Most patients were unemployed (89.8\%) and were unaffiliated with a religion (51.6\%). The majority of patients (52.3\%) lived in city while the rest lived in country. The vast majority $(75.2 \%)$ of the patients had a Junior college education level or lower. Participants whose disease course was longer than 6 months made up $40.8 \%$ of the total. The majority (55.9\%) of patients' chemotherapy course was equal or more than 3 times. Additionally, 194 (63.4\%) of the participants were diagnosed with AML, and 112 (36.6\%) had ALL. The majority (55.2\%) of the patients didn't have other diseases (i.e. hypertension or diabetes). The vast majority $(76.8 \%)$ of the patients were undergoing initial treatment for the condition while, all together, majority of the subjects were in the induction $(46.1 \%)$ or consolidation (37.2\%) treatment stage.

\section{Unmet supportive care needs of adult AL patients}

Table 2 shows the unmet supportive care needs of adult AL patients. The 306 adult AL patients under study showed a variety of unmet SCNs, particularly in the health system and information, and psychological domains. The unmet demand rate for each of the 34-item unmet SCNs, ranges from 17.6 to $81.7 \%$. The median (M) scores and IQR (P75-P25) of each domain are 53.41 (40.91) for the health system and information, 42.50 (37.50) for psychological, 40.00 (35.00) for physical/daily living, 35.00 (35.00) for patient care and support, and $0.00(25.00)$ for the sexuality. A total of $42.8 \%$ of the subjects were categorized with "moderate or high demand" (unmet supportive care needs) as defined in health information domain followed by the psychological domain (29.5\%), physical/daily living need domain (28.4\%), care and support need domain (24.4\%) and Sexual needs domain (5.7\%) being the least (Table 3). Table 4 shows that, of the 10 highest unmet needs, six items are from the health system and information domain, and the top three items include: "being informed about things you can do to help yourself to get well" (81.7\%), "being given information (written, diagrams, drawings) about aspects of managing your illness and side-effects at home" (77.5\%), and "being adequately informed about the benefits and side-effects of treatments before you choose to have them" (70.3\%). All three items with the lowest unmet requirements are from the sexual domain.

\section{Factors associated with unmet supportive care needs}

Supplement 1 shows the results of the univariate analysis of this study, of which nine factors in the domains of unmet SCNs, including marital status, original residence, age, education, occupation, other diseases, chemotherapy course, disease course, and treatment stage. The assignment of each variable is shown in Supplement 2. Table 5 shows the factors associated with unmet supportive care needs of adult AL patients. Original residence, education level, occupation, other diseases, chemotherapy course, disease course and treatment stage were statistically significant in the unmet health system and information domain $(p<0.05)$. Marital status, education level, disease course and treatment stage have statistically significant differences in the psychological domain $(p<0.05)$. Occupation and treatment stage are significant in the phys$\mathrm{ical} /$ daily living domain $(p<0.05)$. Marital status, age, occupation, chemotherapy course, disease course and treatment stage are significantly associated with the level of patient care and support domain $(p<0.05)$. Age is significant in relation to patients' sexual domains $(p<0.05)$.

\section{Association between unmet supportive care needs domains and quality of life}

Table 2 shows that the mean score of overall QoL is $103 \pm 26.27$, with scores in each domain, ranked from high to low: SWB $(18.28 \pm 5.02)$, PWB $(16.35 \pm 6.34)$, EWB $(16.19 \pm 4.85)$, and FWB $(12.53 \pm 6.68)$ and LEUS domain $(40.62 \pm 26.27)$. The SCN domains (excluding social/family status) of adult AL patients negatively correlate with all QoL and overall QoL domains. Table 6 shows the correlations of unmet SCNs with QoL. Negative correlations are found in the overall QoL and physical/daily living, psychological, sexual, patient care and support, and health systems and information domains $(\mathrm{r}=-0.527, p<0.01 ; \mathrm{r}=-0.688, p<0.01 ; \mathrm{r}=-0.170, p<$ $0.01 ; \mathrm{r}=-0.352, p<0.01 ; \mathrm{r}=-0.220, p<0.01)$. 
Table 1 Social-demographic information and clinical characteristics $(n=306)$

\begin{tabular}{|c|c|}
\hline Variables & Sample $\mathrm{n}(\mathrm{C}$ \\
\hline \multicolumn{2}{|l|}{ Gender } \\
\hline Male & $159(52.0)$ \\
\hline Female & $147(48.0)$ \\
\hline \multicolumn{2}{|l|}{ Age (years) } \\
\hline $14 \sim 35$ & $137(44.8)$ \\
\hline $36 \sim 60$ & $128(41.8)$ \\
\hline$>60$ & $41(13.4)$ \\
\hline \multicolumn{2}{|l|}{ Marital status } \\
\hline Married & $227(74.2)$ \\
\hline Not married ${ }^{a}$ & $79(25.8)$ \\
\hline \multicolumn{2}{|l|}{ Original residence } \\
\hline City & $160(52.3)$ \\
\hline Country & $146(47.7)$ \\
\hline \multicolumn{2}{|l|}{ Religion } \\
\hline No & $158(51.6)$ \\
\hline$Y_{e s}^{b}$ & $148(48.4)$ \\
\hline \multicolumn{2}{|l|}{ Occupation } \\
\hline Farmer & $81(26.5)$ \\
\hline General worker & $35(11.4)$ \\
\hline Student & $39(12.7)$ \\
\hline Professionals ${ }^{c}$ & $24(7.8)$ \\
\hline Administrative staff & $26(8.5)$ \\
\hline Businessman & $30(9.8)$ \\
\hline Others $^{d}$ & $71(23.3)$ \\
\hline \multicolumn{2}{|l|}{ Education level } \\
\hline High school and below & $147(48.1)$ \\
\hline Junior college & $83(27.1)$ \\
\hline Bachelor degree or above & $76(24.8)$ \\
\hline \multicolumn{2}{|l|}{ Type of AL } \\
\hline ALL & $112(36.6)$ \\
\hline AML & $194(63.4)$ \\
\hline \multicolumn{2}{|l|}{ Other disease ${ }^{e}$} \\
\hline No & $169(55.2)$ \\
\hline Yes & $137(44.8)$ \\
\hline \multicolumn{2}{|l|}{ Disease course (month) } \\
\hline$\leq 6$ & $181(59.2)$ \\
\hline$>6$ & $125(40.8)$ \\
\hline \multicolumn{2}{|l|}{ Chemotherapy course (times) } \\
\hline $1 \sim 2$ & $135(44.1)$ \\
\hline$\geq 3$ & $171(55.9)$ \\
\hline \multicolumn{2}{|l|}{ Treatment stage } \\
\hline Induction & $141(46.1)$ \\
\hline Consolidation & $114(37.2)$ \\
\hline
\end{tabular}

Table 1 Social-demographic information and clinical characteristics ( $n=306)$ (Continued)

\begin{tabular}{ll}
\hline Variables & Sample $\mathrm{n}(\%)$ \\
\hline Maintenance $^{\mathrm{f}}$ & $51(16.7)$ \\
Initial treatment or not & \\
Yes & $235(76.8)$ \\
No & $71(23.2)$ \\
\hline
\end{tabular}

AL Acute leukemia, AML Acute myelogenous leukemia, ALL Acute lymphoblastic leukemia

${ }^{a}$ Not married includes single, widow, and divorced

${ }^{\mathrm{b}}$ Refer to practice a religion

c Refer to engineers, doctors, nurses, teachers and other senior

professional/technical workers

$\mathrm{d}$ Others includes retirement

e Refer to other primary diseases or chronic diseases except acute

leukemia complications

${ }^{f}$ Refer to support and symptomatic treatment of acute leukemia therapy

\section{Discussion}

To our knowledge, this is the first study in mainland China that has identified an association between unmet SCNs and the QoL of adult AL patients. The following three aspects will be discussed, based on the objectives and results of the research: (i) the unmet SCNs of adult AL patients, (ii) factors associated with the unmet SCNs of adult AL patients and (iii) the relationship between unmet SCNs and the QoL of adult AL patients in mainland China.

\section{The unmet SCNs of adult AL patients}

The results show that the health systems and information domain scores the highest of the five domains, which is consistent with the results of previous studies $[13,37,38]$. Information needs are concerned with treatment for most cancer patients [39]. This may be because knowledge of diseaserelated information can affect patients' confidence and self-efficacy in facing the disease, and also reflects their eagerness to understand initiatives to fight it. This serves as a reminder that healthcare professionals should pay more attention to providing adequate and effective informational support to patients, as they follow the disease trajectory.

The psychological domain of SCNs ranked second in this study, which is consistent with previous studies [13], with $76.8 \%$ patients reporting the item of "concerns about the worries of those close to you". Previous studies $[34,40]$ have demonstrated that the item with the highest demand score in the psychological domain is "fear of cancer recurrence or spread", which is inconsistent with the results of this study, and possibly due to the differences between $\mathrm{AL}$ and a solid tumour, or a limited sample size. The physical/daily living domain ranked third of the SCNs. Generally, ALs present several clinical symptoms, including fever, fatigue, bleeding, and infections, which is consistent with previous studies [41]. Long 
Table 2 Unmet supportive care needs and quality of life scores in all domains $(n=306)$

\begin{tabular}{|c|c|c|c|c|c|}
\hline Domain & Entry & Min & Max & Mean (SD) & $\mathrm{M}(\mathrm{IQR})$ \\
\hline \multicolumn{6}{|l|}{ FACT-Leu } \\
\hline Physical Well-Being & 7 & 0.00 & 28.00 & $16.35(6.34)$ & $17.00(9.00)$ \\
\hline Social/Family Well-Being & 7 & 5.00 & 28.00 & $18.28(5.02)$ & $19.00(6.00)$ \\
\hline Emotional Well-Being & 6 & 0.00 & 24.00 & $16.19(4.85)$ & $17.00(7.00)$ \\
\hline Functional Well-Being & 7 & 0.00 & 28.00 & $12.53(6.68)$ & $13.00(10.00)$ \\
\hline LEUS domain & 17 & 4.00 & 65.00 & $40.62(11.70)$ & $42.00(15.00)$ \\
\hline Overall QOL & 44 & 16.00 & 167.00 & $103.97(26.27)$ & $106.00(32.25)$ \\
\hline \multicolumn{6}{|l|}{ Unmet SCNs } \\
\hline Health systems and information needs & 11 & 0.00 & 100.00 & $54.78(24.60)$ & $53.41(40.91)$ \\
\hline Psychological & 10 & 0.00 & 100.00 & $43.07(24.24)$ & $42.50(37.50)$ \\
\hline Physical/daily living & 5 & 0.00 & 100.00 & $41.63(23.35)$ & $40.00(35.00)$ \\
\hline Patient care and support & 5 & 0.00 & 95.00 & $38.35(22.33)$ & $35.00(35.00)$ \\
\hline Sexuality & 3 & 0.00 & 100.00 & $14.73(20.420$ & $0.00(25.00)$ \\
\hline
\end{tabular}

FACT-LEU Chinese Version of Functional Assessment of Cancer Therapy-Leukemia; The leukemia-specific subscale is called the LEUS domain in this article; Unmet SCNs: The Supportive Care Needs Survey form; QOL Quality of life, SD Standard deviation, M Median, IQR Interquartile range (P75-P25)

periods of hospitalization may also increase the psychological burden on patients.

In the patient care and support domain, our research finds the highest reported item is "more choice about which cancer specialists you see", which may result from patients' uncertainty regarding the treatment of the disease and their anticipated life expectancy. In terms of the sexual domain, the results of this study are consistent with previous research [13, 35]. For AL patients, treating the disease and managing symptoms is more important than their sexual lives, which can pose potential risks. The nature and the specificity of AL (e.g., bleeding, infection, etc.) may also increase patient concerns about the influence of the disease on their sexual life, in the context of Chinese culture.

The findings indicate that healthcare professionals should pay special attention to patients' unmet supportive care needs, especially information and psychological needs. On the other hand, more effective interventions can be implemented to meet the needs of patients in a timely and effective manner.

\section{The factors associated with the unmet SCNs of adult AL patients}

Our study reveals that the domains of the unmet SCNs of adult AL patients, depend on eight factors, including marital status, age, education level, occupation, presence of other diseases the disease course, chemotherapy course and treatment stage.

In terms of the participant's marital status, $\mathrm{SCNs}$ are less for married people, which is consistent with the findings of previous studies [42]. However, it has been demonstrated that the emotional needs of divorced/ widowed patients are significantly less than others, whereas the emotional needs of unmarried cancer patients remain unmet $[35,43]$. These inconsistent results may be due to limited samples, or different cancer types. Previous literature on the impact of age on patient care, categorizes support needs differently. Our study finds that older patients ( $>60$ years old) demand more care and support than younger patients (18-35 years old). Some studies have shown that older people recover slowly during treatment because of their physical

Table 3 Scoring level of unmet supportive care needs in each dimension $(n=306)$

\begin{tabular}{|c|c|c|c|c|c|c|}
\hline Domain of SCNs & Not Applicable (\%) & Satisfield (\%) & Low (\%) & $\begin{array}{l}\text { Moderate } \\
\text { (\%) }\end{array}$ & $\begin{array}{l}\text { High } \\
(\%)\end{array}$ & Total $^{a}(\%)$ \\
\hline Health systems and information & 13.2 & 21.2 & 22.8 & 19.1 & 23.7 & 42.8 \\
\hline Psychological & 26.4 & 16.7 & 27.3 & 17.8 & 11.7 & 29.5 \\
\hline Physical/daily living & 28.3 & 16.2 & 27.1 & 17.3 & 11.1 & 28.4 \\
\hline Patient care and support & 24.3 & 33.4 & 17.9 & 14.0 & 10.4 & 24.4 \\
\hline Sexuality & 67.5 & 13.8 & 13.0 & 3.5 & 2.2 & 5.7 \\
\hline
\end{tabular}

SCNs Supportive care needs

${ }^{a}$ Sum of the percentage of moderate to high need 
Table 4 Sequence of items of unmet supportive needs $(n=34)$

\begin{tabular}{|c|c|c|c|c|}
\hline Order $^{a}$ & Item & Domain & Mean (SD) & $\%^{\mathrm{b}}$ \\
\hline 1 & Being informed about things you can do to help yourself to get well & I & $3.81(1.26)$ & 81.70 \\
\hline 2 & $\begin{array}{l}\text { Being given information (written, diagrams, drawings) about aspects of managing your illness } \\
\text { and side-effects at home }\end{array}$ & । & $3.22(1.20)$ & 77.50 \\
\hline 5 & $\begin{array}{l}\text { Being adequately informed about the benefifits and side-effects of treatments before you } \\
\text { choose to have them }\end{array}$ & । & $3.38(1.33)$ & 70.30 \\
\hline 6 & $\begin{array}{l}\text { Having access to professional counselling (e.g., psychologist, social worker, counselor, nurse specialist) } \\
\text { if you, family or friends need it }\end{array}$ & । & $3.13(1.39)$ & 69.60 \\
\hline 9 & Being informed about your test results as soon as feasible & । & $3.40(1.34)$ & 68.30 \\
\hline 10 & $\begin{array}{l}\text { Having one member of hospital staff with whom you can talk to about all aspects of your condition, } \\
\text { treatment and follow-up }\end{array}$ & । & $3.07(1.34)$ & 67.00 \\
\hline 12 & Being given written information about the important aspects of your care & । & $2.96(1.26)$ & 65.00 \\
\hline 13 & Being informed about cancer which is under control or diminishing (that is, remission) & । & $3.36(1.37)$ & 63.70 \\
\hline 14 & Being given explanations of those tests for which you would like explanations & । & $3.22(1.31)$ & 63.10 \\
\hline 20 & Being treated in a hospital or clinic that is as physically pleasant as possible & । & $2.94(1.45)$ & 52.90 \\
\hline 27 & Being treated like a person not just another case & । & $2.61(1.35)$ & 43.50 \\
\hline 3 & Concerns about the worries of those close to you & $\mathrm{P}$ & $3.39(1.22)$ & 76.80 \\
\hline 4 & Uncertainty about the future & $\mathrm{P}$ & $2.87(1.42)$ & 72.20 \\
\hline 8 & Feelings about death and dying & P & $2.54(1.39)$ & 68.60 \\
\hline 11 & Worry that the results of treatment are beyond your control & $P$ & $3.00(1.34)$ & 66.30 \\
\hline 17 & Feeling down or depressed & $P$ & $2.55(1.23)$ & 56.20 \\
\hline 18 & Learning of feel in control of your situation & $P$ & $2.71(1.28)$ & 54.90 \\
\hline 19 & Fears about the cancer spreading & $P$ & $2.62(1.41)$ & 53.90 \\
\hline 21 & Anxiety & $\mathrm{P}$ & $2.45(1.27)$ & 52.00 \\
\hline 22 & Feelings of sadness & $P$ & $2.42(1.22)$ & 50.30 \\
\hline 23 & Keeping a positive outlook & $P$ & $2.61(1.31)$ & 49.70 \\
\hline 7 & Lack of energy/tiredness & $\mathrm{H}$ & $3.00(1.17)$ & 68.60 \\
\hline 15 & Feeling unwell a lot of the time & $\mathrm{H}$ & $2.76(1.26)$ & 61.80 \\
\hline 16 & Not being able to do the things you used to do & $\mathrm{H}$ & $2.77(1.39)$ & 58.80 \\
\hline 26 & Pain & $\mathrm{H}$ & $2.55(1.42)$ & 46.10 \\
\hline 30 & Work around the home & $\mathrm{H}$ & $2.25(1.34)$ & 42.20 \\
\hline 24 & More choice about which cancer specialists you see & S & $2.71(1.44)$ & 48.70 \\
\hline 25 & Hospital staff acknowledging, and showing sensitively to, your feelings and emotional needs & S & $2.56(1.75)$ & 47.70 \\
\hline 28 & More choice about which hospital you attend & $\mathrm{S}$ & $2.55(1.39)$ & 43.50 \\
\hline 29 & Hospital staff attending promptly to your physical needs & S & $2.61(1.24)$ & 42.50 \\
\hline 31 & Reassurance by medical staff that the way you feel is normal & S & $2.20(1.08)$ & 29.10 \\
\hline 32 & Being given information about sexual relationships & $x$ & $1.60(1.03)$ & 19.60 \\
\hline 33 & Changes in sexual feelings & $x$ & $1.59(0.94)$ & 18.60 \\
\hline 34 & Changes in your sexual relationships & $x$ & $1.57(0.99)$ & 17.60 \\
\hline
\end{tabular}

$I$ Health systems and information needs, $P$ Psychological, $H$ Physical/daily living, S Patient care and support, $X$ Sexuality. SD Standard deviation

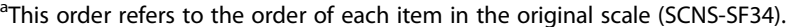

${ }^{\mathrm{b}}$ The unmet demand rate of each item $=$ Number of patients with unmet support needs for this item/ Total number of patients who answered the item $\times 100 \%$.

condition and, therefore, require additional care and support [44], whereas other studies report that younger patients have more unmet SCNs [45]. The probable cause may be greater demand from younger cancer patients for information about body image and interpersonal relationships.
In this study, education level was related to patients' psychological and sexual needs. This may be because higher levels of education improve a patient's selfefficacy and self-regulation ability. However, the evidence supporting the findings is limited. Our study finds that farmers have greater information needs than 
Table 5 Multivariate logistic regression analysis on the factors of unmet supportive needs in all domains $(n=306)$

\begin{tabular}{|c|c|c|c|c|c|c|c|}
\hline Domain of SCNs & Variable & B & SE & Wald & $O R$ & $95 \% \mathrm{Cl}$ & $P$ \\
\hline \multirow[t]{9}{*}{ Health systems and information } & Occupation & & & & & & \\
\hline & Farmer & Ref & - & - & 1.00 & - & - \\
\hline & Businessman & -1.71 & 0.65 & 6.95 & 0.18 & $0.05 \sim 0.65$ & 0.008 \\
\hline & Other disease & & & & & & \\
\hline & No & Ref & - & - & 1.00 & - & - \\
\hline & Yes & 0.84 & 0.35 & 5.71 & 2.32 & $1.16 \sim 4.62$ & 0.017 \\
\hline & Disease course (month) & & & & & & \\
\hline & $\leq 6$ & Ref & - & - & 1.00 & - & - \\
\hline & $>6$ & -1.01 & 0.40 & 6.29 & 0.36 & $0.17 \sim 0.80$ & 0.012 \\
\hline \multirow[t]{13}{*}{ Psychological } & Marital status & & & & & & \\
\hline & Married & Ref & - & - & 1.00 & - & - \\
\hline & Not married & 0.81 & 0.34 & 5.71 & 2.24 & $1.16 \sim 4.35$ & 0.017 \\
\hline & Education & & & & & & \\
\hline & Bachelor degree or above & Ref & - & - & 1.00 & - & - \\
\hline & Junior college & 0.89 & 0.37 & 5.84 & 2.43 & $1.18 \sim 5.00$ & 0.016 \\
\hline & High school and below & 0.84 & 0.32 & 6.83 & 2.32 & $1.24 \sim 4.38$ & 0.009 \\
\hline & Disease course (month) & & & & & & \\
\hline & $\leq 6$ & Ref & - & - & 1.00 & - & - \\
\hline & $>6$ & -0.73 & 0.29 & 6.60 & 0.48 & $0.28 \sim 0.84$ & 0.01 \\
\hline & Treatment stage & & & & & & \\
\hline & Induction & Ref & - & - & 1.00 & - & - \\
\hline & Consolidation & -1.32 & 0.46 & 8.17 & 0.27 & $0.11 \sim 0.66$ & 0.004 \\
\hline \multirow[t]{8}{*}{ Physical/daily living } & Occupation & & & & & & \\
\hline & Farmer & Ref & - & - & 1.00 & - & - \\
\hline & Student & -1.02 & 0.42 & 5.96 & 0.36 & $0.16 \sim 0.82$ & 0.015 \\
\hline & Professionals & -1.08 & 0.51 & 4.46 & 0.34 & $0.13 \sim 0.93$ & 0.035 \\
\hline & Others & -0.77 & 0.35 & 4.86 & 0.46 & $0.23 \sim 0.92$ & 0.027 \\
\hline & Treatment stage & & & & & & \\
\hline & Induction & Ref & - & - & 1.00 & - & - \\
\hline & Consolidation & -0.79 & 0.28 & 7.87 & 0.45 & $0.26 \sim 0.79$ & 0.005 \\
\hline \multirow[t]{12}{*}{ Patient care and support } & Marital status & & & & & & \\
\hline & Married & Ref & - & - & 1.00 & - & - \\
\hline & Not married & 0.93 & 0.31 & 8.92 & 2.53 & $1.38 \sim 4.65$ & 0.003 \\
\hline & Age(year) & & & & & & \\
\hline & $18 \sim 35$ & Ref & - & - & 1.00 & - & - \\
\hline & $>60$ & 1.31 & 0.48 & 7.36 & 3.69 & 1.44 9.46 & 0.007 \\
\hline & Chemotherapy course (times) & & & & & & \\
\hline & $1 \sim 2$ & Ref & - & - & 1.00 & - & - \\
\hline & $\geq 3$ & -1.05 & 0.34 & 9.51 & 0.35 & $0.18 \sim 0.68$ & 0.002 \\
\hline & Treatment stage & & & & & & \\
\hline & Induction & Ref & - & - & 1.00 & - & - \\
\hline & Consolidation & -0.73 & 0.26 & 8.04 & 0.48 & $0.29 \sim 0.80$ & 0.010 \\
\hline \multirow[t]{3}{*}{ Sexuality } & Education & & & & & & \\
\hline & Bachelor degree or above & Ref & - & - & 1.00 & - & - \\
\hline & Junior college & 1.27 & 0.61 & 4.38 & 3.55 & 1.08 11.63 & 0.036 \\
\hline
\end{tabular}

The results of first step regression analysis (including all variables) and the final model for each domain were given in supplement 1 SCNs supportive care needs 
Table 6 Spearman correlations ( $r$ ) between unmet supportive needs and quality of life $(n=306)$

\begin{tabular}{lllllll}
\hline Domain & PWB & SWB & EWB & FWB & LEUS domain & Overall QOL \\
\hline Health systems and information needs & $-0.259^{* *}$ & 0.003 & $-0.183^{* *}$ & $-0.135^{*}$ & $-0.252^{* *}$ & $-0.220^{* *}$ \\
Psychological & $-0.594^{* *}$ & -0.066 & $-0.702^{* *}$ & $-0.469^{* *}$ & $-0.572^{* *}$ & $-0.688^{* *}$ \\
Physical/daily living & $-0.531^{* *}$ & -0.043 & $-0.344^{* *}$ & $-0.359^{* *}$ & $-0.505^{* *}$ & $-0.527^{* *}$ \\
Patient care and support & $-0.354^{* *}$ & -0.076 & $-0.296^{* *}$ & $-0.284^{* *}$ & $-0.301^{* *}$ & $-0.352^{* *}$ \\
Sexuality & $-0.271^{* *}$ & -0.064 & $-0.168^{* *}$ & $-0.132^{*}$ & $-0.163^{* *}$ & $-0.170^{* *}$ \\
\hline
\end{tabular}

businessmen, similar to a previous study [46]. This may be partially explained by businessmen having greater access to social resources and additional channels to obtain information, than farmers. Further rigorous study is required to verify these findings.

Our research finds that the unmet needs of AL patients with other diseases, are greater than those of $\mathrm{AL}$ patients without other diseases, which is consistent with a previous study [47]. The results also indicate that the duration of the disease may affect unmet SCNs in consolidation and strengthening, which is consistent with a previous study [48]. Patients with fewer than two courses of chemotherapy show more unmet SCNs, which may be partially explained by the higher uncertainty of the disease experienced by patients during initial treatment, as it may raise concerns about the side effects. In this study, patients undergoing induced remission were at higher risk of unmet SCNs than those undergoing consolidation. Most patients with health system and information needs had relatively long disease courses (>6 months), which conflicts with a previous study [13]. Therefore, the evidence for a relationship between the disease course and adult AL patients, and unmet $\mathrm{SCNs}$, requires further validation.

\section{The relationship between unmet SCNs and QoL in adult AL patients}

Understanding the relationship between unmet supportive care needs and QoL, in adult AL patients, is a stepping stone to improving QoL [24]. This study shows that all domains of a patient's unmet SCNs negatively correlate with QoL (excluding social/family status) and overall QoL. Although cancer patients' QoL is influenced by the burden of disease-related symptoms and distress [37], unmet SCNs may partially explain the variance in QoL for adult AL patients. The more patients have unmet needs, the worse their QoL, as found by a previous study [49]. Additionally, the characteristics of susceptibility to recurrence, financial burden and high mortality, impair the mental health of patients and exacerbate their psychological needs. High levels of impaired physical and psychological unmet needs can severely affect a patient's QoL [50]. One study suggests that clinicians can use needs assessment tools to assess patients' QoL [51]. Early assessment of unmet supportive care needs and the provision of appropriate services can enhance patient QoL [52].

In summary, understanding the current unmet SCNs of patients can be a screening problem for patients, improving medical services and providing progress on the development of clinical care decisions and interventions [53]. Although the mechanisms of interaction between unmet SCNs and QoL are unclear, studies have shown that interventions for unmet SCNs in adult AL patients may be an effective method to improve their QoL [54]. The results of this study cannot be generalized to other types of cancer patients, who are entitled to a different cultural backgrounds and social security benefits.

\section{Study limitations}

First, this study was conducted at three tertiary hospitals in Fuzhou, which may lead to institutional bias and limit the generality of the findings. Second, the study design is cross-sectional and may not be representative of the overall unmet SCNs of adult AL cancer patients in China. The cross-sectional design cannot establish causality. Third, patients' unmet SCNs may be influenced by different cultural backgrounds and medical systems, limiting the generality of the result to populations of patients with other types of cancer. Finally, patients' responses to unmet SCNs and QoL may be influenced by treatment regimens, side effects of chemotherapy, stressful life events, mental health at the time, and satisfaction with medical care.

\section{Implications for practice}

The findings suggest some potential implications for practice. First, screening patients for unmet SCNs throughout treatment, is important for these patients to reduce their disease-related burden and risk of depression. Second, the factors affecting SCNs may be important entry points for nursing interventions. Healthcare professionals should detect patients' unmet SCNs as early as possible, and provide targeted care for the influencing factors of unmet SCNs, to improve the QoL of adult AL patients. Finally, mobile medicine is strongly recommended to solve the problem of insufficient clinical nursing resources in meeting the unmet SCNs of patients. 


\section{Conclusion}

This study contributes to the knowledge of the relationship between unmet SCNs and the QoL of adult AL patients in China. Our results suggest that healthcare professionals need to seek effective interventions to meet the needs of patients, improve QoL, and intervene based on these underlying factors. Future research should explore other risk factors affecting SCNs at different stages of the disease, and to develop coordinated resources and programs to address the unmet SCNs of adult AL patients with different cultural characteristics.

\section{Supplementary information}

Supplementary information accompanies this paper at https://doi.org/10. 1186/s12955-020-01454-5.

Additional file 1: Supplement 1. Univariate analysis of supportive

needs in patients with acute leukemia.

Additional file 2: Supplement 2. The included variable assignment of multiple regression

\section{Abbreviations}

AL: Acute leukemia; ALL: Acute lymphoblastic leukemia; AML: Acute myelogenous leukemia; EWB: Emotional Well-Being; FACT-LEU: Chinese Version of Functional Assessment of Cancer Therapy-Leukemia; FWB: Functional Well-Being; IQR: Interquartile range (P75-P25); LEUS domain: The leukemia-specific subscale of FACT-leu; PWB: Physical WellBeing; QoL: Quality of life; SCNs: Supportive care needs; SWB: Social/Family Well-Being; SD: Standard deviation

\section{Acknowledgments}

The authors are especially grateful to Hairong Zhang for his kind help in statistics. The authors gratefully thank the support from the related hospitals and all the participants for their contribution in this study. The authors have full control of all primary data and agree to allow the journal to review the data, if necessary.

\section{Authors' contributions}

Ying Wang and Jie Yan have contributed to the work equally. Rong Hu was responsible for the study conception and design. Ying Wang, Jie Yan, Jingyi Chen \& Chunfeng Wang contributed to data acquisition, analysis, and interpretation. Ying Wang and Rong Hu were responsible for manuscript preparation. Yingchun Lin contributed to the review of the data. Rong Hu and Yong Wu contributed to the critical revision of the manuscript, obtained funding, and supervised the research. The authors read and approved the final manuscript.

\section{Funding}

This study was supported by the Scientific Research Talents Training Project from Fujian Province Health Commission, China (Grant No. 2018-ZQN-63) and Nature Science Foundation of Fujian Provincial (Grant No. 2019 J01684)

\section{Availability of data and materials}

The data that support the findings of this study are available on request from the corresponding author.

\section{Ethics approval and consent to participate}

The study protocol was approved by the Biological and Medical Research Ethics Committee of Fujian Medical University (IRB Ref No: 2017/00049),

Fujian Medical University Union Hospital, the First Affiliated Hospital of Fujian University, and Fujian Provincial Hospital in, September 2017. No study procedures were performed prior to obtaining all participants' written and informed consent.

\section{Consent for publication}

Not applicable.

\section{Competing interests}

The authors declare no potential competing interests.

\section{Author details}

${ }^{1}$ School of Nursing, Fujian Medical University, NO.1 Xueyuan Road, Shangjie Town, Minhou County, Fuzhou City 350122, Fujian Province, China.

${ }^{2}$ Department of Hematology, the First Affiliated Hospital of Fujian University, No. 20 of Chazhong Road, Taijiang District, Fuzhou City 350004, Fujian Province, China. ${ }^{3}$ Department of Hematology, Fujian Medical University Union Hospital, No. 29 Xinquan Road, Gulou District, Fuzhou City 350001, Fujian Province, China.

Received: 23 February 2020 Accepted: 16 June 2020

Published online: 23 June 2020

\section{References}

1. Miranda-Filho A, Piñeros M, Ferlay J, Soerjomataram I, Monnereau A, Bray F. Epidemiological patterns of leukaemia in 184 countries: a population-based study. Lancet Haematol. 2018;5:e14-24.

2. Bray F, Ferlay J, Soerjomataram I, Siegel RL, Torre LA, Jemal A. Global cancer statistics 2018: GLOBOCAN estimates of incidence and mortality worldwide for 36 cancers in 185 countries. CA Cancer J Clin. 2018;68:394-424.

3. Chen W, Zheng R, Baade PD, Zhang S, Zeng H, Bray F, et al. Cancer statistics in China, 2015. CA Cancer J Clin. 2016;66:115-32.

4. Cancer Stat Facts: Leukemia [https://seer.cancer.gov/statfacts/html/leuks.html].

5. Albrecht TA. Physiologic and psychological symptoms experienced by adults with acute leukemia: an integrative literature review. Oncol Nurs Forum. 2014;41:286-95.

6. Leak Bryant A, Walton AL, Pergolotti M, Phillips B, Bailey C, Mayer DK, et al. Perceived benefits and barriers to exercise for recently treated adults with acute leukemia. Oncol Nurs Forum. 2017:44:413-20.

7. Cameron K. Review:chemotherapy plus supportive care improves survival and quality of life in advanced or metastatic gastrointestinal cancer more than supportive care alone. Evid Based Nurs. 2005:8:18.

8. Albrecht TA, Boyiadzis M, Elswick RK Jr, Starkweather A, Rosenzweig M. Symptom management and psychosocial needs of adults with acute myeloid leukemia during induction treatment: a pilot study. Cancer Nurs. 2017;:40:E31-8.

9. Leak Bryant A, Lee Walton A, Shaw-Kokot J, Mayer DK, Reeve BB. Patientreported symptoms and quality of life in adults with acute leukemia: a systematic review. Oncol Nurs Forum. 2015;42:E91-E101.

10. Jarrett N, Scott I, Addington-Hall J, Amir Z, Brearley S, Hodges L, et al. Informing future research priorities into the psychological and social problems faced by cancer survivors: a rapid review and synthesis of the literature. Eur J Oncol Nurs. 2013;17:510-20.

11. Stein KD, Syrjala KL, Andrykowski MA. Physical and psychological long-term and late effects of cancer. Cancer. 2008;112:2577-92.

12. Hui D. Definition of supportive care: does the semantic matter? Curr Opin Oncol. 2014;26:372-9.

13. Yu FF, Bai YN, He H, Zhu L, Zhang RL, Jiao HX, et al. Identifying the unmet supportive care needs, with concomitant influencing factors, in adult acute leukemia patients in China. Eur J Oncol Nurs. 2017:30:67-74.

14. Lam WWT, Tsang J, Yeo W, Suen J, Ho WM, Yau TK, et al. The evolution of supportive care needs trajectories in women with advanced breast cancer during the 12 months following diagnosis. Support Care Cancer. 2013;22: 635-44.

15. Chen SC, Chiou SC, Yu CJ, Lee YH, Liao WY, Hsieh PY, et al. The unmet supportive care needs-what advanced lung cancer patients' caregivers need and related factors. Support Care Cancer. 2016;24:2999-3009.

16. Umezawa S, Fujisawa D, Fujimori M, Ogawa A, Matsushima E, Miyashita M. Prevalence, associated factors and source of support concerning supportive care needs among Japanese cancer survivors. Psycho-Oncology. 2015;24: 635-42.

17. Richardson A. Improving supportive and palliative care for adults with cancer. Nurs Times. 2003;99:49.

18. So WK, Chow KM, Chan HY, Choi KC, Wan RW, Mak SS, et al. Quality of life and most prevalent unmet needs of Chinese breast cancer survivors at one year after cancer treatment. Eur J Oncol Nurs. 2014;18:323-8.

19. Galvão DA, Newton RU, Gardiner RA, Girgis A, Lepore SJ, Stiller A, et al. Compliance to exercise-oncology guidelines in prostate cancer survivors 
and associations with psychological distress, unmet supportive care needs, and quality of life. Psycho-Oncology. 2015;24(10):1241-9.

20. Wang C, Yan J, Chen J, Wang Y, Lin YC, Hu R, et al. Factors associated with quality of life of adult patients with acute leukemia and their family caregivers in China: a cross-sectional study. Health Qual Life Outcomes. 2020;18:8.

21. Cramarossa G, Chow E, Zhang L, Bedard G, Zeng L, Sahgal A, et al. Predictive factors for overall quality of life in patients with advanced cancer. Support Care Cancer. 2013;21:1709-16.

22. Simon AE, Thompson MR, Flashman K, Wardle J. Disease stage and psychosocial outcomes in colorectal cancer. Colorectal Dis. 2009;11:19-25.

23. Siddiqi A, Given CW, Given B, Sikorskii A. Quality of life among patients with primary, metastatic and recurrent cancer. Eur J Cancer Care (Engl). 2009;18: 84-96.

24. Doubova SV, Casales-Hernandez MG, Perez-Cuevas R. Supportive care needs and association with quality of life of Mexican adults with solid cancers. Cancer Nurs. 2018:41:E1-E12.

25. Galvao DA, Newton RU, Gardiner RA, Girgis A, Lepore SJ, Stiller A, et al. Compliance to exercise-oncology guidelines in prostate cancer survivors and associations with psychological distress, unmet supportive care needs, and quality of life. Psychooncology. 2015;24:1241-9.

26. Jordan K, Aapro M, Kaasa S, Ripamonti Cl, Scotte F, Strasser F, et al. European Society for Medical Oncology (ESMO) position paper on supportive and palliative care. Ann Oncol. 2018;29:36-43.

27. Smith $A B$, King $M$, Butow $P$, Luckett $T$, Grimison $P$, Toner $G C$, et al. The prevalence and correlates of supportive care needs in testicular cancer survivors: a cross-sectional study. Psychooncology. 2013;22:2557-64.

28. Lam WW, Au AH, Wong JH, Lehmann C, Koch U, Fielding R, et al. Unmet supportive care needs: a cross-cultural comparison between Hong Kong Chinese and German Caucasian women with breast cancer. Breast Cancer Res Treat. 2011;130:531-41.

29. Cossich T, Schofield P, McLachlan SA. Validation of the cancer needs questionnaire (CNQ) short-form version in an ambulatory cancer setting. Qual Life Res. 2004;13:1225-33.

30. ML W. Statistical analysis of questionnaires: SPSS operation and application Chongqing: Chongqing University Press; 2010

31. Fayers PM. MD: quality of life: assessment, analysis and interpretation. Chichester: Wiley; 2000

32. Kerr LM, Harrison MB, Medves J, Tranmer J. Supportive care needs of parents of children with cancer: transition from diagnosis to treatment. Oncol Nurs Forum. 2004;31:E116-26.

33. Mcelduff PBA, Zucca A, Girgis A. Supportive care needs survey: a guide to administration, scoring and analysis. Ency Qual Life Well-Being Res. 2004. https://doi.org/10.1007/978-94-007-0753-5_3942.

34. Boyes A, Girgis A, Lecathelinais C. Brief assessment of adult cancer patients' perceived needs: development and validation of the 34-item supportive care needs survey (SCNS-SF34). J Eval Clin Pract. 2009;15:602-6.

35. Au A, Lam W, Tsang J, Yau TK, Soong I, Yeo W, et al. Supportive care needs in Hong Kong Chinese women confronting advanced breast cancer. Psychooncology. 2013;22:1144-51.

36. Meng Q, Yang Z, Wu Y, Xiao Y, Gu X, Zhang M, et al. Reliability analysis of the Chinese version of the functional assessment of cancer therapy leukemia (FACT-Leu) scale based on multivariate generalizability theory. Health Qual Life Outcomes. 2017;15:93.

37. Cheng KKF, Wong WH, Koh C. Unmet needs mediate the relationship between symptoms and quality of life in breast cancer survivors. Support Care Cancer. 2016:24:2025-33.

38. Armes J, Crowe M, Colbourne L, Morgan H, Murrells T, Oakley C, et al. Patients' supportive care needs beyond the end of cancer treatment: a prospective, longitudinal survey. J Clin Oncol. 2009;27:6172-9.

39. Rutten LJ, Arora NK, Bakos AD, Aziz N, Rowland J. Information needs and sources of information among cancer patients: a systematic review of research (1980-2003). Patient Educ Couns. 2005;57:250-61.

40. Schmid-Buchi S, Halfens RJ, Muller M, Dassen T, van den Borne B. Factors associated with supportive care needs of patients under treatment for breast cancer. Eur J Oncol Nurs. 2013;17:22-9.

41. Williams LAGA, Ahaneku HO, Cortes JE, Garciamanero G, Kantarjian HM, Mendoza TR, et al. A patient-reported outcome measure for symptoms and symptom burden of acute myeloid leukemia (AML) and myelodysplastic syndrome (MDS). Blood. 2015;126:2094.
42. Rainbird K, Perkins J, Sanson-Fisher R, Rolfe I, Anseline P. The needs of patients with advanced, incurable cancer. Br J Cancer. 2009;101:759-64.

43. Voogt E, van der Heide A, van Leeuwen AF, Visser AP, Cleiren MP, Passchier $J$, et al. Positive and negative affect after diagnosis of advanced cancer. Psychooncology. 2005;14:262-73.

44. Ream E, Quennell A, Fincham L, Faithfull S, Khoo V, Wilson-Barnett J, et al. Supportive care needs of men living with prostate cancer in England: a survey. Br J Cancer. 2008;98:1903-9.

45. Li Q, Lin Y, Zhou H, Xu Y, Xu Y. Supportive care needs and associated factors among Chinese cancer survivors: a cross-sectional study. Support Care Cancer. 2019:27:287-95.

46. Sanson-Fisher RGA, Boyes A, Bonevski B, Burton L, Cook P. The unmet supportive care needs of patients with cancer. Supportive care review group. Cancer. 2015;88:226-37.

47. Beesley WWL, Rourke P, Janda M, Goldstein D, Gooden H, Merrett N, et al. Risk factors for current and future unmet supportive care needs of people with pancreatic cancer. A longitudinal study. Support Care Cancer. 2016;24: 3589-99.

48. Chen SC, Lai YH, Liao CT, Chang JT, Lin CY, Fan KH, et al. Supportive care needs in newly diagnosed oral cavity cancer patients receiving radiation therapy. Psychooncology. 2013;22:1220-8.

49. So WK, Chan CW, Choi KC, Wan RW, Mak SS, Chair SY. Perceived unmet needs and health-related quality of life of Chinese cancer survivors at 1 year after treatment. Cancer Nurs. 2013:36:E23-32.

50. Piazza MF, Galletta M, Portoghese I, Pilia I, Ionta MT, Contu P, et al. Meeting psychosocial and health information needs to ensure quality of cancer care in outpatients. Eur J Oncol Nurs. 2017;29:98-105.

51. Akechi T, Okuyama T, Endo C, Sagawa R, Uchida M, Nakaguchi T, et al. Patient's perceived need and psychological distress and/or quality of life in ambulatory breast cancer patients in Japan. Psychooncology. 2011;20:497-505.

52. Oh J, Kim SH, Kim JA. Unmet supportive care needs mediate the relationship betweenfunctional status and quality of life in patients with amyotrophic lateral sclerosis. Palliat Support Care. 2019;17(6):650-4.

53. Holm LV, Hansen DG, Larsen PV, Johansen C, Vedsted P, Bergholdt SH, et al. Social inequality in cancer rehabilitation: a population-based cohort study. Acta Oncol. 2013;52:410-22.

54. Snyder CFBA, Brahmer JR, Carducci MA, Pili R, Stearns V, Wolff AC, et al. Needs assessments can identify scores on HRQOL questionnaires that represent problems for patients_an illustration with the supportive care needs survey and the QLQ-C30. Qual Life Res. 2010;19:837-45.

\section{Publisher's Note}

Springer Nature remains neutral with regard to jurisdictional claims in published maps and institutional affiliations.
Ready to submit your research? Choose BMC and benefit from:

- fast, convenient online submission

- thorough peer review by experienced researchers in your field

- rapid publication on acceptance

- support for research data, including large and complex data types

- gold Open Access which fosters wider collaboration and increased citations

- maximum visibility for your research: over $100 \mathrm{M}$ website views per year

At $\mathrm{BMC}$, research is always in progress.

Learn more biomedcentral.com/submissions 